\title{
Current trends in tuberculosis mortality in England and Wales
}

\author{
Mohamed Nisar, P D O Davies
}

\begin{abstract}
To determine current trends in mortality from tuberculosis according to age the published data on notification and deaths from tuberculosis from 1974 to 1987 have been analysed. The ratio of deaths to notifications per year was assessed over this period as a measure of case fatality from tuberculosis. The mean annual decline in the ratio for each age group was as follows: $0-14$ years $6.7 \%$ (95\% confidence interval 4.00 to $9.6 \%$ ), $15-34$ years $1.4 \%(-0.2$ to $3.0 \%), 35-54$ years $4.5 \%(2 \cdot 2$ to $6.9 \%), 55-74$ years $2 \cdot 8 \%$ $(1.8$ to $3.7 \%)$, and 75 + years $3 \cdot 2 \%(2 \cdot 1$ to $4 \cdot 2 \%)$. Because the incidence of disease in the $75+$ group has declined much more slowly than in the rest of the population and because the size of this age group has increased in relation to the other groups, the overall annual mortality from tuberculosis has declined by only $0.13 \%(95 \% \mathrm{CI}-1 \cdot 3$ to $1 \cdot 3 \%)$. The total number of deaths from tuberculosis declined from 996 in 1974 to 430 in 1987, whereas deaths in the $75+$ age group remained relatively constant at around 200 a year.
\end{abstract}

There has been considerable improvement and rationalisation in the chemotherapy of tuberculosis in recent years, ${ }^{12}$ with more clinicians adopting the shorter course regimens and including pyrazinamide in their drug regimen. Despite this there appears to have been little overall improvement in the mortality from this disease in England and Wales. ${ }^{34}$ Current trends in notifications suggest that, whereas the disease in the younger half of the population continues to decline at an annual rate of about $8 \%$, the incidence of disease in the elderly is diminishing little if at all. An increase in the total numbers of elderly patients with tuberculosis, where frailty and general disability may result in increased mortality, could produce an overall increase in mortality, despite a decrease in each age group considered separately. Thus there is an impression that the apparent lack of improvement in mortality may be due to a continuing high mortality from tuberculosis in the elderly, ${ }^{3}$ who constitute an increasing proportion of the population as a whole. ${ }^{5}$ Mortality rates are a measure of deaths per unit of total population and may not reflect the number of patients with disease. They do not necessarily therefore on their own provide evidence of improved diagnosis and management of disease. The ratio of deaths from disease to total numbers with that disease (a measure of case fatality) provides a clearer means of assessing how well tuberculosis is being managed.

In an attempt to quantify trends in tuberculosis case fatality in recent years, we have determined the death to notification ratio from published data.

\section{Methods}

National data for notifications of and deaths from tuberculosis (all forms but late effects excluded) have been extracted from the relevant Office of Population Census and Surveys (OPCS) monitors for the years 1974 $87 .{ }^{67}$ Notification data are derived from notification of disease by individual clinicians to their local consultant in communicable disease control (formerly the medical officer for environmental health). Data on cause of death are derived from death certificates supplied to the Registrar General.

Deaths from the late effects of tuberculosis have not been included in the analysis. Data for the years 1974-83 have been corrected for the change in coding, which became effective in 1984 , on the basis of the bridge coding exercise of the OPCS, ${ }^{8}$ so that any trends in mortality in the period 1974-87 may be determined accurately. We have expressed mortality from tuberculosis as the ratio of deaths per year divided by notifications for that year (DNR). This is a measure of case fatality and is distinct from the standard notification ratio, which expresses notifications per 100 deaths. We have analysed data for age groups $0-14,15-34,35-$ $54,55-74$, and $75+$ separately but have combined the sexes. Published standard notification ratio data use only three age groups. ${ }^{6}$ Many cases of chemoprophylaxis were included in notification data before $1983 .{ }^{9}$ Thus an overestimate of notifications of about $3 \%$ in the younger age group for the years 1974-83 may have occurred. ${ }^{10}$ The net effect may therefore have been to overestimate notifications in children for the years $1974-83$ and thus to underestimate the deaths to notifications ratio for those years.

ANALYSIS

The percentage annual decline in the ratio of deaths to notification (DNR) for each age group by year were expressed by the regression equation

$$
y=c+b x
$$


Table 1 Numbers of notifications $(N)$ and corrected numbers of deaths (CD) in the different age groups from 1974 to 1987, with data for the $75+$ age group expressed as a percentage of the totals for all ages

\begin{tabular}{|c|c|c|c|c|c|c|c|c|c|c|c|c|c|c|}
\hline \multirow[b]{3}{*}{ Year } & \multicolumn{10}{|c|}{ Age group (y) } & & & & \\
\hline & \multicolumn{2}{|l|}{$0-14$} & \multicolumn{2}{|l|}{$15-34$} & \multicolumn{2}{|l|}{$35-54$} & \multicolumn{2}{|l|}{$55-74$} & \multicolumn{2}{|l|}{$75+$} & \multicolumn{2}{|c|}{ All ages } & \multicolumn{2}{|c|}{$\begin{array}{l}75+\text { age group } \\
\text { as } \% \text { of all ages }\end{array}$} \\
\hline & $N$ & $C D$ & $N$ & $C D$ & $N$ & $C D$ & $N$ & $C D$ & $N$ & $C D$ & $N$ & $C D$ & $\%$ of $N$ & $\%$ of $C D$ \\
\hline 1974 & 1144 & 18 & 3273 & 35 & 3130 & 206 & 2476 & 500 & 524 & 257 & 10677 & 996 & $4 \cdot 9$ & $25 \cdot 8$ \\
\hline 1975 & 1088 & 13 & 3416 & 35 & 3126 & 163 & 2487 & 452 & 614 & 332 & 10818 & 915 & $5 \cdot 7$ & $36 \cdot 3$ \\
\hline 1976 & 1020 & 12 & 3147 & 28 & 2925 & 144 & 2394 & 401 & 553 & 257 & 10098 & 803 & $5 \cdot 5$ & 31.9 \\
\hline 1977 & 972 & 7 & 3029 & 18 & 2666 & 112 & 2207 & 344 & 562 & 240 & 9520 & 680 & 5.9 & $35 \cdot 3$ \\
\hline 1978 & 903 & 7 & 3208 & 17 & 2606 & 108 & 2323 & 334 & 540 & 204 & 9682 & 739 & $5 \cdot 6$ & 27.6 \\
\hline 1979 & 944 & 4 & 3003 & 20 & 2532 & 92 & 2143 & 330 & 550 & 228 & 9266 & 646 & 5.9 & $35 \cdot 3$ \\
\hline 1980 & 961 & 4 & 2971 & 23 & 2342 & 102 & 2185 & 326 & 572 & 208 & 9142 & 663 & $6 \cdot 3$ & $31 \cdot 4$ \\
\hline 1981 & 790 & 4 & 2531 & 21 & 2110 & 81 & 2042 & 296 & 546 & 210 & 8128 & 612 & $6 \cdot 7$ & $34 \cdot 3$ \\
\hline 1982 & 619 & 2 & 2300 & 15 & 1797 & 85 & 1936 & 291 & 615 & 229 & 7406 & 621 & $8 \cdot 3$ & 36.9 \\
\hline 1983 & 617 & 4 & 2004 & 7 & 1678 & 56 & 1796 & 244 & 612 & 206 & 6800 & 492 & $9 \cdot 0$ & 41.9 \\
\hline 1984 & 596 & 4 & 1738 & 14 & 1496 & 56 & 1639 & 208 & 578 & 207 & 6141 & 490 & $9 \cdot 4$ & $42 \cdot 2$ \\
\hline 1985 & 431 & 3 & 1663 & 16 & 1372 & 47 & 1660 & 235 & 625 & 222 & 5857 & 523 & $10 \cdot 7$ & $42 \cdot 4$ \\
\hline 1986 & 485 & 3 & 1745 & 13 & 1443 & 43 & 1615 & 200 & 598 & 212 & 5992 & 471 & $10 \cdot 0$ & $45 \cdot 0$ \\
\hline 1987 & 439 & 2 & 1453 & 13 & 1255 & 49 & 1320 & 191 & 532 & 175 & 5085 & 430 & 10.5 & $40 \cdot 7$ \\
\hline
\end{tabular}

where $y$ is $\log _{\mathrm{e}} \mathrm{DNR}, c$ is the intercept on the $y$ axis, $x$ is the year studied, and $b$ is $\log _{\mathrm{e}}$ of the slope.

$\left(\mathrm{I}-\mathrm{e}^{\mathrm{b}}\right)$ is then equal to the average annual rate of decline in the deaths to notifications ratio expressed as a percentage. Confidence limits were calculated as described. ${ }^{11}$

\section{Results}

The notifications and corrected deaths from tuberculosis by age group and for all ages combined for each year are shown in table 1 . Notifications and corrected deaths in the $75+$ age group are also expressed as a proportion of total notifications and deaths. The average percentage decline per annum for each age group with the $95 \%$ confidence intervals is given in table 2 and the ratio of deaths to notifications for 1979-87 in the figure. For all age groups combined the deaths to notifications ratio changed little over the 14 years of the study, declining by only $0.13 \%$ per annum (table 2), a rate that does not differ significantly from zero. The deaths to notifications ratio for each age group, however, declined significantly except in the $15-34$ age group $(1.4 \%$ (CI $-0 \cdot 2$ to $3.0 \%))$. The decline among children $(0-14$ years) is steepest at $6.7 \%$ (CI $4.0 \%$ to $9.6 \%$ ) a year, though numbers are small. In adults aged 35-54 the decline was $4.5 \%$ a year. There was also a significant downward annual trend in the $55-74$ age group $(2 \cdot 8 \%)$ and in patients aged 75 years or more $(3 \cdot 2 \%)$.

In 1974 the $75+$ age group yielded $4.9 \%$ of all notifications and accounted for $26 \%$ of all deaths. By 1987 the proportion of notifications in the $75+$ age group had more than doubled, to over $10 \%$ (table 1 ), and mortality had risen to $45 \%$ in 1986 and $41 \%$ in 1987 , an average increase of $3 \cdot 2 \%(95 \%$ CI $1 \cdot 7$ to $4 \cdot 8 \%)$ a year. The total number of deaths from tuberculosis at all ages halved from 996 in 1974 to 430 in 1987 (table 1).

\section{Discussion}

Despite a satisfactory decline in the ratio of deaths to notifications from tuberculosis for each age group, the ratio for all age groups combined has shown virtually no change. This is due to the increasing proportion of tuberculosis in the elderly ( $75+$ years), where mortality is highest. ${ }^{12}$ Most patients who die from tuberculosis do so shortly after treatment has started. In a recent study half of the deaths occurred within two weeks of the start of treatment and $90 \%$ within six months. ${ }^{3}$ For the purposes of this study we have assumed that patients dying from tuberculosis are likely to have been notified as having the disease within a relatively short period around the time of death-in some cases actually after death.

Patients "not notified before death" were not included in notification statistics before 1985 . Since this anomaly was pointed out ${ }^{9}$ this number, which has never been very great, has probably amounted to less than 10 a year (OPCS, personal communication).

Deaths from late effects of tuberculosis were specifically excluded as such patients may have been notified many years previously. The possible underestimate of mortality as a result of this exclusion is likely to be minimal as very few patients are likely to have been notified and treated for tuberculosis since 1974 with severe residual effects causing death after more than

Table 2 Average decline per annum of the ratio of deaths to notifications with $95 \%$ confidence intervals for the different age groups and for all ages combined

\begin{tabular}{|c|c|c|c|c|c|c|}
\hline & \multicolumn{5}{|c|}{ Age group (y) } & \multirow[b]{2}{*}{ All ages } \\
\hline & $0-14$ & $15-34$ & $35-54$ & $55-74$ & $75+$ & \\
\hline \multirow{2}{*}{$\begin{array}{l}\% \text { decline } \\
\text { per annum } \\
(95 \% \mathrm{CI})\end{array}$} & & & & & & \\
\hline & $\begin{array}{l}6 \cdot 7 \\
(4 \cdot 0 \text { to } 9 \cdot 6)\end{array}$ & $\begin{array}{l}1 \cdot 4 \\
(-0.2 \text { to } 3 \cdot 0)\end{array}$ & $\begin{array}{l}4 \cdot 5 \\
(2 \cdot 2 \text { to } 6 \cdot 9)\end{array}$ & $\begin{array}{l}2 \cdot 8 \\
(1 \cdot 8 \text { to } 3 \cdot 7)\end{array}$ & $\begin{array}{l}3 \cdot 2 \\
(2 \cdot 1 \text { to } 4 \cdot 2)\end{array}$ & $\begin{array}{l}0 \cdot 13 \\
(-1 \cdot 3 \text { to } 1.3)\end{array}$ \\
\hline
\end{tabular}




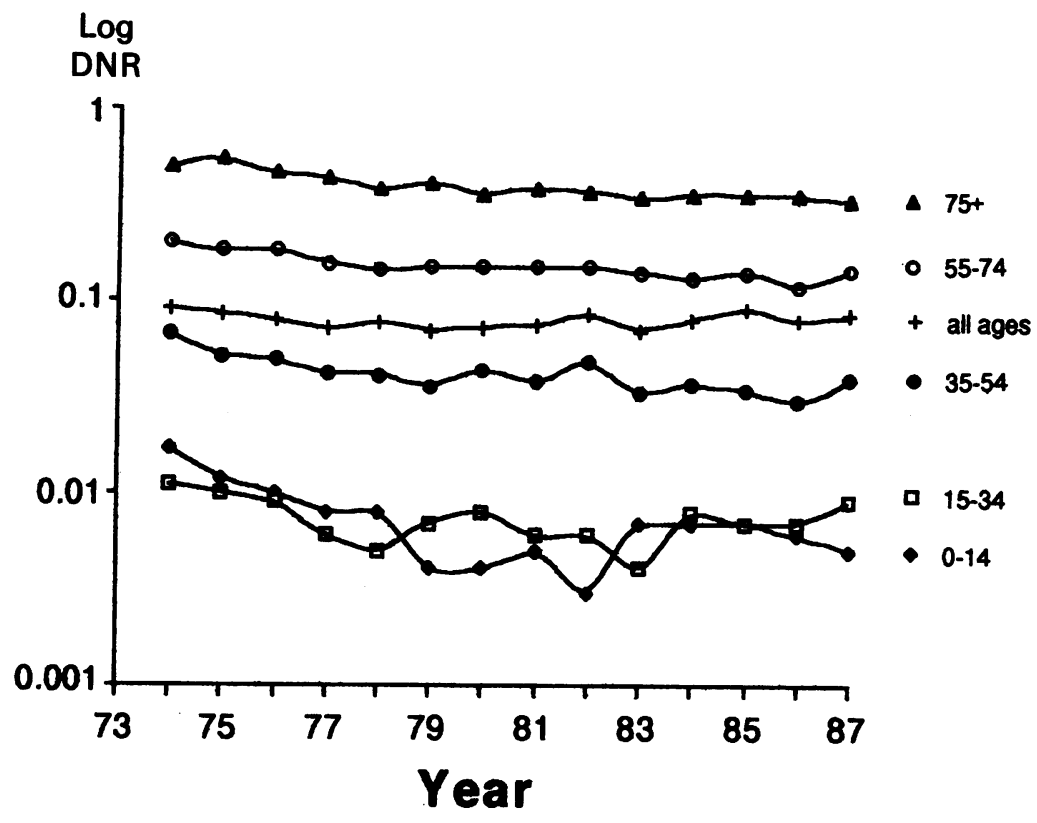

Log plot of deaths to notifications ratio ( $\log$ DNR) for the study period 1974-87 for the different age groups and all ages combined. subcontinent ethnic origin, ${ }^{15}$ few of these are as yet in the $75+$ age group. Most deaths from tuberculosis in the very elderly occur in the indigenous white population. ${ }^{3}$ Some of the increasing proportion of new cases of tuberculosis in the $75+$ age group may present to geriatricians rather than chest physicians. All clinicians need to be alerted to the possibility of tuberculosis, especially those specialising in diseases of the elderly, if the fall in fatality rate is to be maintained. Probably most cases of tuberculosis in the elderly are due to recrudescence of infection, often contracted many years earlier. ${ }^{5}$ Most will therefore occur spontaneously and not be detected through routine contact tracing. A relatively high proportion may present as disseminated or cryptic miliary disease.

The elderly are living increasingly in communal residential and nursing homes, where they may be at increased risk from tuberculosis according to surveys carried out in the United States. ${ }^{16}$ Further study to estimate prevalence of tuberculosis and to define rates of infection in this age group would therefore seem worthwhile.

one year. The effects of this exclusion on the ratio of deaths to notifications will therefore be insignificant. Both notification and mortality may be underreported, especially in the elderly, though this potential inaccuracy is difficult to quantify. The downward trends in the ratio of deaths to notifications are consistent and probably give an accurate assessment of the overall trends in fatality of tuberculosis over the years studied.

It is encouraging that the fatality rate has improved for almost all age groups, suggesting that the diagnosis and treatment of tuberculosis in England and Wales is improving. That this is particularly so in children (0-14 years) may suggest a greater awareness of the possibility of tuberculosis and better management by those concerned with child health. Numbers, however, are very small (table 1 ). The reason for the virtually static fatality rate in the 15-34 age group is not clear and needs further clarification. This age group may contain a higher proportion of notifications of patients of Indian subcontinent ethnic origin than do other age groups. Although mortality from pulmonary disease in this ethnic group is low, ${ }^{3}$ extrapulmonary disease occurs in a greater proportion of these patients and no published data are available on deaths from extrapulmonary disease by ethnic origin.

The problem of tuberculosis in the elderly has been well described and the high mortality rates in such patients noted previously. ${ }^{313}$ The population aged $75+$ in England and Wales increased by $30 \%$ between 1974 and $1987 .^{14}$ The total number of notifications and deaths in the elderly has remained remarkably constant over the same period (table 1) and the notification and mortality rates in this population have actually declined by $30 \%$. Although $45 \%$ of cases of tuberculosis occur in patients of Indian
We would like to thank Nicola Moon for typing the manuscript and Dr Deborah Ashby, Liverpool University, for statistical assistance. MN is funded by the British Lung Foundation.

1 Medical Research Council Tuberculosis and Chest Diseases Unit. Treatment of pulmonary tuberculosis in patients notified in England and Wales in 1978-9: chemotherapy and hospital admissions. Thorax 1985;40:113-20.

2 Medical Research Council Tuberculosis and Chest Diseases Unit. Management and outcome of pulmonary tuberculosis in adults notified in England and Wales in 1983. Thorax 1988;43:591-8.

3 Humphries MJ, Byfield SP, Darbyshire JH, et al. Deaths occurring in newly notified patients with pulmonary tuberculosis in England and Wales. Br J Dis Chest 1984 78:149-57.

4 Cullinan P, McDonald SK, Byfield SP, et al. Deaths in patients with pulmonary tuberculosis in England and Wales, 1983 [abstract]. Thorax 1988;43:855P.

5 Davies PDO. The slowing of the decline in tuberculosis notifications and HIV infection. Respir Med 1989;83: 321-2.

6 Office of Population Census and Surveys. Communicable diseases 1974-1987. London: HMSO, 1975-88. (Series MB2, Nos 1-14.)

7 Office of Population Census and Surveys. Mortality statistics (cause). London: HMSO, 1975-1988. (Series DH2, Nos 1-14.)

8 Office of Population Census and Surveys. Mortality statistics. London: HMSO, 1985. (Series DH2, No 11.)

9 Office of Population Census and Surveys. Communicable diseases statistics 1982. London: HMSO, 1983. (Series MB2, No 9.)

10 Davies PDO, Darbyshire JH, Nunn AJ, et al. Ambiguities and inaccuracies in the notification system for tuberculosis in England and Wales. Commun Med 1981;3:108-18.

11 Gardner JM, Altman DG. Statistics with confidence. London: British Medical Association, 1989:37.

12 Springett VH, Darbyshire JH, Nunn AJ, Sutherland I. Changes in tuberculosis notification rates in the white Changes in tuberculosis notification rates in the white
ethnic group in England and Wales between 1953 and ethnic group in England and Wales between

13 McKay AD, Cole RB. The problem of tuberculosis in the elderly. $Q J$ Med 1984;212:497-510.

14 Office of Population Census and Surveys. Population estimates. London: HMSO, 1983. (Series PP1, No 6.)

15 Medical Research Council Tuberculosis and Chest Disease Unit. National survey of tuberculosis notifications in England and Wales 1983. Characteristics of disease. Tubercle 1987;68:19-32.

16 Stead WW, Lofgren JP, Warren E, et al. Tuberculosis as an endemic and nosocomial infection among the elderly in nursing homes. N Engl J Med 1985;312:1483-7. 